Daniel Varecha - Slavomir Hrcek - Otakar Bokuvka - Frantisek Novy - Libor Trsko - Ruzica Nikolic - Michal Jambor

\title{
FATIGUE SAFETY COEFFICIENTS FOR ULTRA - HIGH REGION OF LOAD CYCLES
}

In this paper the authors introduce results from the field of the fatigue safety of selected steels in the region of ultra - high number of loading cycles. The fatigue tests were carried out at high frequency tension - compression loading $\left(f=20 \mathrm{kHz}, T=20 \pm 5^{\circ}, R=-1\right)$ in the region from $N=10^{6}$ to $N=10^{9}$ cycles. The fatigue safety coefficients were calculated by four methods (Goodman, Gerber, ASME elliptic and Soderberg). The percentage reduction of the fatigue safety coefficients $\left(N=10^{9} \mathrm{vs} . N=10^{6}\right.$ cycles $)$ was at Goodman, $7.99 \div 10.83 \%$, Gerber, 5.27 $\div 8.26 \%$, ASME, $1.89 \div 6.42 \%$ and Soderberg, $6.51 \div 10.25 \%$.

Keywords: structural steels, ultra - high cycles fatigue, safety coefficients

\section{Introduction}

Fatigue is the dominant degradation mechanism during the operation of components and mechanical constructions. More than $90 \%$ of all the fractures are caused by fatigue of the applied material. Targeted research, both theoretical and experimental, of the low - cycle and high - cycle fatigue of structural steels, began in the mid $-19^{\text {th }}$ century. For the area of the high cycle fatigue, the fatigue limit $\sigma_{c}$ was defined as the largest fluctuating stress at certain mean stress $\sigma_{m}$ that the structural steel withstands for an infinite number of cycles. For steels, the so - called basic number of cycles $\mathrm{N}_{c}$, in the range from $\mathrm{N}_{c}=10^{6}$ to $10^{7}$ cycles, was recommended for an infinite number of cycles. However, research institutes have demonstrably noticed that fractures caused by fatigue occur in structural steels far beyond the so - called basic number $\mathrm{N}_{\mathrm{c}}=10^{7}$ cycles. Conclusions on the safe loading and permanent fatigue strength beyond this cycle limit are inaccurate and incomplete. In view of this fact, at the end of the $20^{\text {th }}$ century, both theoretical and experimental research of ultra - high - cycle fatigue, in the range from $\mathrm{N}=10^{7}$ to $\mathrm{N}$ $=10^{10}$ loading cycles, began. Questions are being verified, such as what is the course of dependence $\sigma_{a}=f(N)$, the physical nature of the fatigue limit $\sigma_{c}$, the existence of the fatigue limit, degradation fatigue mechanisms at very low values of the plastic deformation amplitude, propagation of short fatigue cracks at extremely low rates, the role of inclusions, long grain boundaries, pores, surface and subsurface initiation of fatigue cracks, etc. after the so - called basic number $\mathrm{N}_{\mathrm{c}}=10^{7}$ load cycles in structural steels. The course of the dependence $\sigma_{a}=f(N)$, including the step - wise or duplex curves with a "plato" is discussed [1-7]. High - graded steels of medium and high strengths are used in various industries. They have a specific place in the field of rails, tires, wings and hull transport. With regard to this state area of application, these steels are required to have a long service life and high reliability and safety, [8]. Determining the fatigue safety factor is important both from a theoretical point of view and from a practical point of view [9-13]. In this paper the authors introduce their own results from the field of the fatigue safety of selected steels in the region of ultra - high number of loading cycles.

\section{Experimental}

Experimental works, the qualitative and quantitative chemical analysis, tensile tests, fatigue test and the fatigue coefficient $k_{u}$ calculations, were carried out on eight structural steels including high strength steels (DOMEX 700MC, HARDOX 400, HARDOX 450). Chemical analysis was performed with help of the emission spectrometry on an ICP (JY 385) emission spectrometer, using a fast recording system Image. Tensile tests were carried out on a ZWICK Z050 testing machine at ambient temperature of $\mathrm{T}=20 \pm 5{ }^{\circ} \mathrm{C}$, with the loading range in interval $\mathrm{F}=0-20$ $\mathrm{kN}$ and the strain rate of $\dot{\varepsilon}_{m}=10^{-3} \mathrm{~s}^{-1}$. The round cross - section specimens were used, the shape and dimension of specimens have met requirements of the EN $10002-1$ standard (3 specimens for each steel were used). The fatigue tests were carried out at high - frequency sinusoidal cyclic tension - compression loading ( $\mathrm{f}=20 \mathrm{kHz}, \mathrm{T}=20 \pm 5^{\circ} \mathrm{C}$, $\mathrm{R}=-1$, cooled by distilled water with anticorrosive inhibitor) and with use of the ultrasonic fatigue testing device. Smooth round bar specimens (minimum 10 pieces) with diameter of $4 \mathrm{~mm}$, ground and polished by metallographic procedures, were used for the fatigue test [14-15]. The investigated

\footnotetext{
Daniel Varecha ${ }^{1}$, , Slavomir Hrcek ${ }^{1}$, Otakar Bokuvka ${ }^{1}$, Frantisek Novy ${ }^{1}$, Libor Trsko ${ }^{2}$, Ruzica Nikolic ${ }^{2}$, Michal Jambor ${ }^{3}$

${ }^{1}$ Faculty of Mechanical Engineering, University of Zilina, Slovak Republic

${ }^{2}$ Research Centre, University of Zilina, Slovak Republic

${ }^{3}$ Institute of Physics of Materials, Brno, Czech Republic

*E-mail of corresponding author: daniel.varecha@fstroj.uniza.sk
} 


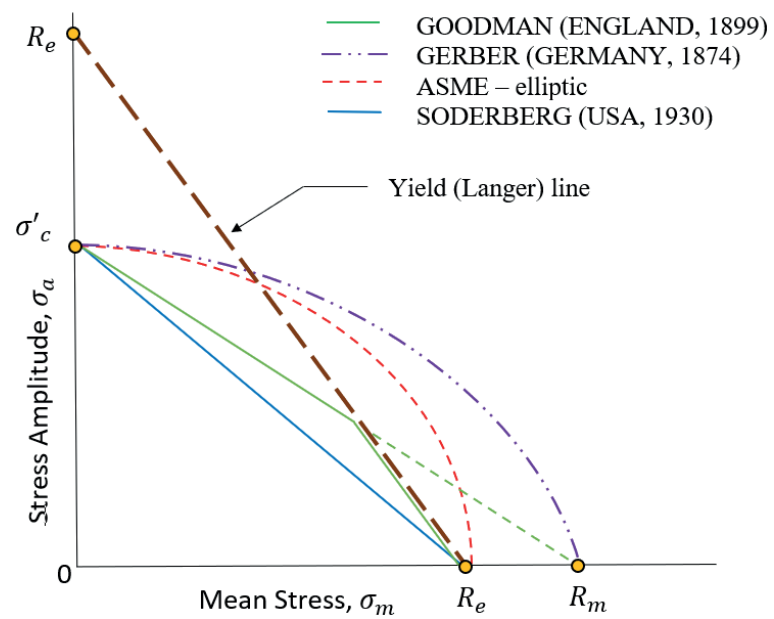

Figure $1 \sigma_{a}=f\left(\sigma_{m}\right)[12]$

Table 1 Mechanical properties of tested structural steels

\begin{tabular}{ccccc}
\hline Steel & $R_{e}(\mathrm{MPa})$ & $R_{m}(\mathrm{MPa})$ & $\sigma_{a}, 10^{6}(\mathrm{MPa})$ & $\sigma_{a}, 10^{9}(\mathrm{MPa})$ \\
\hline 1 & 340 & 446 & 285 & 201 \\
2 & 376 & 564 & 352 & 210 \\
3 & 251 & 773 & 408 & 288 \\
4 & 796 & 850 & 425 & 265 \\
5 & 710 & 867 & 390 & 288 \\
6 & 750 & 952 & 548 & 350 \\
7 & 1226 & 1257 & 500 & 352 \\
8 & 1425 & 1560 & 551 & 400 \\
\hline
\end{tabular}

Table 2 Chemical composition (in weight \%) of tested structural steels

\begin{tabular}{cccccccccccccccc}
\hline Steel & $\mathrm{C}$ & $\mathrm{Mn}$ & $\mathrm{Si}$ & $\mathrm{N}$ & $\mathrm{Ti}$ & $\mathrm{Al}$ & $\mathrm{Mo}$ & $\mathrm{Cr}$ & $\mathrm{Ni}$ & $\mathrm{Cu}$ & $\mathrm{P}$ & $\mathrm{S}$ & $\mathrm{Nb}$ & $\mathrm{V}$ & $\mathrm{B}$ \\
\hline 1 & 0.17 & 0.51 & 0.17 & - & - & - & - & 0.03 & 0.04 & 0.06 & 0.013 & 0.013 & - & - & - \\
2 & 0.18 & 1.47 & 0.03 & - & - & - & - & 0.03 & 0.02 & 0.04 & 0.015 & 0.011 & - & - & - \\
3 & 0.058 & 1.63 & 0.81 & - & 0.37 & - & 2.54 & 17.55 & 12.96 & - & 0.033 & 0.037 & - & - & - \\
4 & 0.08 & 1.67 & 0.35 & - & 0.015 & 0.015 & - & - & - & - & 0.018 & 0.0037 & 0.06 & 0.014 & - \\
5 & 0.08 & 1.62 & 0.12 & 0.061 & 0.17 & 0.049 & 0.14 & - & - & - & 0.030 & 0.025 & - & - & - \\
6 & 0.52 & 0.70 & 0.34 & - & - & - & - & 0.16 & 0.06 & 0.15 & 0.008 & 0.005 & - & - & - \\
7 & 0.13 & 0.95 & 0.30 & - & - & - & 0.04 & 0.25 & 0.06 & - & 0.012 & 0.002 & - & - & 0.002 \\
8 & 0.20 & 0.80 & 0.39 & - & - & - & 0.01 & 0.45 & 0.05 & - & 0.005 & 0.005 & - & - & 0.001 \\
\hline
\end{tabular}

region of number of cycles ranged from $\mathrm{N} \approx 10^{6}$ to $10^{9}$ cycles of loading.

The fatigue safety coefficient was calculated with regard to work [12], Figure 1, with the using equations: (1) Goodman, (2) Gerber, (3) ASME and (4) Soderberg.

$$
\begin{aligned}
& k_{u}=\frac{1}{\frac{\sigma_{a}}{\sigma_{c}^{\prime}}+\frac{\sigma_{m}}{R_{m}}}, \\
& k_{u}=\frac{1}{2}\left(\frac{R_{m}}{\sigma_{m}}\right)^{2} \frac{\sigma_{a}}{\sigma_{c}^{\prime}}\left[-1+\sqrt{1+\left(\frac{2 \cdot \sigma_{m} \cdot \sigma_{c}^{\prime}}{R_{m} \cdot \sigma_{a}}\right)}\right]
\end{aligned}
$$

(1) where:

$\sigma_{a}$ is the stress amplitude,

$\sigma_{m}$ is the mean stress,

$\sigma_{c}^{\prime}$ is the fatigue limit,

(2) $R_{m}$ is the ultimate tensile strength,

$R_{e}$ is the yield point. 

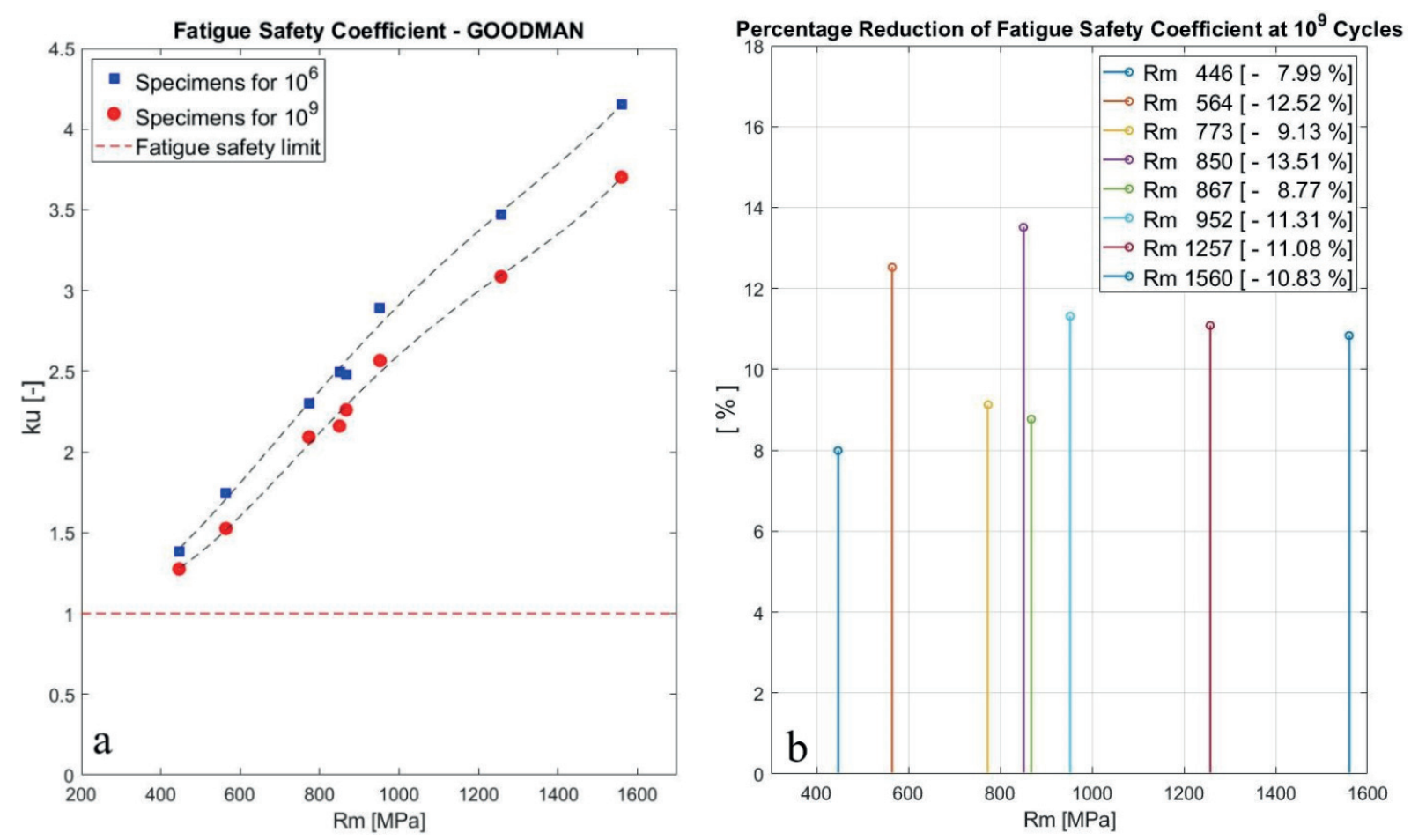

Figure 2 Fatigue safety coefficient $k_{u}(a)$ and percentage reduction of $k_{u}(b)$ - Goodman

Table 3 Specimens for the safety coefficient $k_{u}$ for Goodman

\begin{tabular}{cccccccccc}
\hline Specimens & 1 & 2 & 3 & 4 & 5 & 6 & 7 & 8 \\
\hline$k_{u}$ for $10^{6}$ & 1.39 & 1.75 & 2.3 & 2.5 & 2.48 & 2.89 & 3.47 & 4.15 \\
$k_{u}$ for $10^{9}$ & 1.27 & 1.53 & 2.09 & 2.16 & 2.26 & 2.57 & 3.08 & 3.70 \\
\hline \% Reduction $k_{u}$ & -7.99 & -12.52 & -9.13 & -13.51 & -8.77 & -11.31 & -11.08 & -10.83 \\
\hline
\end{tabular}

Application of the above described experimental work was executed on a screw joint, which is, during the operation, loaded by a cyclic stress in superposition with the preload. The material parameters of the screw were taken from Table 1, where values of $R_{e}$ and $R_{m}$ of experimental materials are given.

\section{Results and discussion}

Results of qualitative and quantitative chemical analysis (chemical composition), tensile tests (ultimate tensile strength $\mathrm{R}_{\mathrm{m}}$, yield point $\mathrm{R}_{\mathrm{e}}$ ) and high - frequency fatigue tests $\left(\sigma_{a}, 10^{6}, \sigma_{a}, 10^{9}\right)$, are shown in Tables 1 and 2 , respectively. Results of the fatigue safety coefficient $k_{u}$ calculations are shown in Figures 2 to 5 and also in Tables 3 to 6 .

Material fatigue tests have demonstrably confirmed a continuous decrease in fatigue strength in the investigated range of the number of the loading cycles. The step - wise or duplex $\sigma_{a}=f(N)$ curves were not observed. The observed values of $\Delta \sigma_{a}$ ranged from $\Delta \sigma_{a}=84 \mathrm{MPa}$ to $\Delta \sigma_{a}=198 \mathrm{MPa}$. Values $\Delta \sigma_{a}$ in the region of the ultra - high number of loading cycles for steels range from $\Delta \sigma_{a}=20 \mathrm{MPa}$ to $\Delta \sigma_{a}=200 \mathrm{MPa}$. Higher values of $\Delta \sigma_{a}$ were exhibited by the structural steels of higher strength, what is related to their higher sensitivity to both surface and internal defects (micro - impurity, microstructural heterogeneity, pores, grain size, inclusions). These statements are in accordance with the works of the authors [1-7, 9].

It is clear from results (Figures 2 to 5 , Tables 3 to 6) that Goodman and Soderberg methods are suitable methods (criteria) for evaluation of the fatigue safety of selected structural steels in the region of the high number of cycles. The Soderberg criterion checks the occurrence of any deformation. Lower values of $k_{u}$ ensure that no fatigue failure or accidents would occur during the considered ultra - high number of load cycles. The Goodman criterion is very strict, but it is one of the best known criteria that allows for a simple analytical solution of fatigue tasks. The American Society of Mechanical Engineers (ASME) has addressed the issue of fatigue safety, which is a more conservative criterion but does not have sufficient margin to determine the fatigue safety coefficient for an ultra - high number $\mathrm{N}=10^{9}$ of cycles. The Gerber criterion seems to be the least suitable, because approaching the limit state of fatigue safety and at an ultra - high number of cycles fatigue fracture accidents can occur [9-13]. 

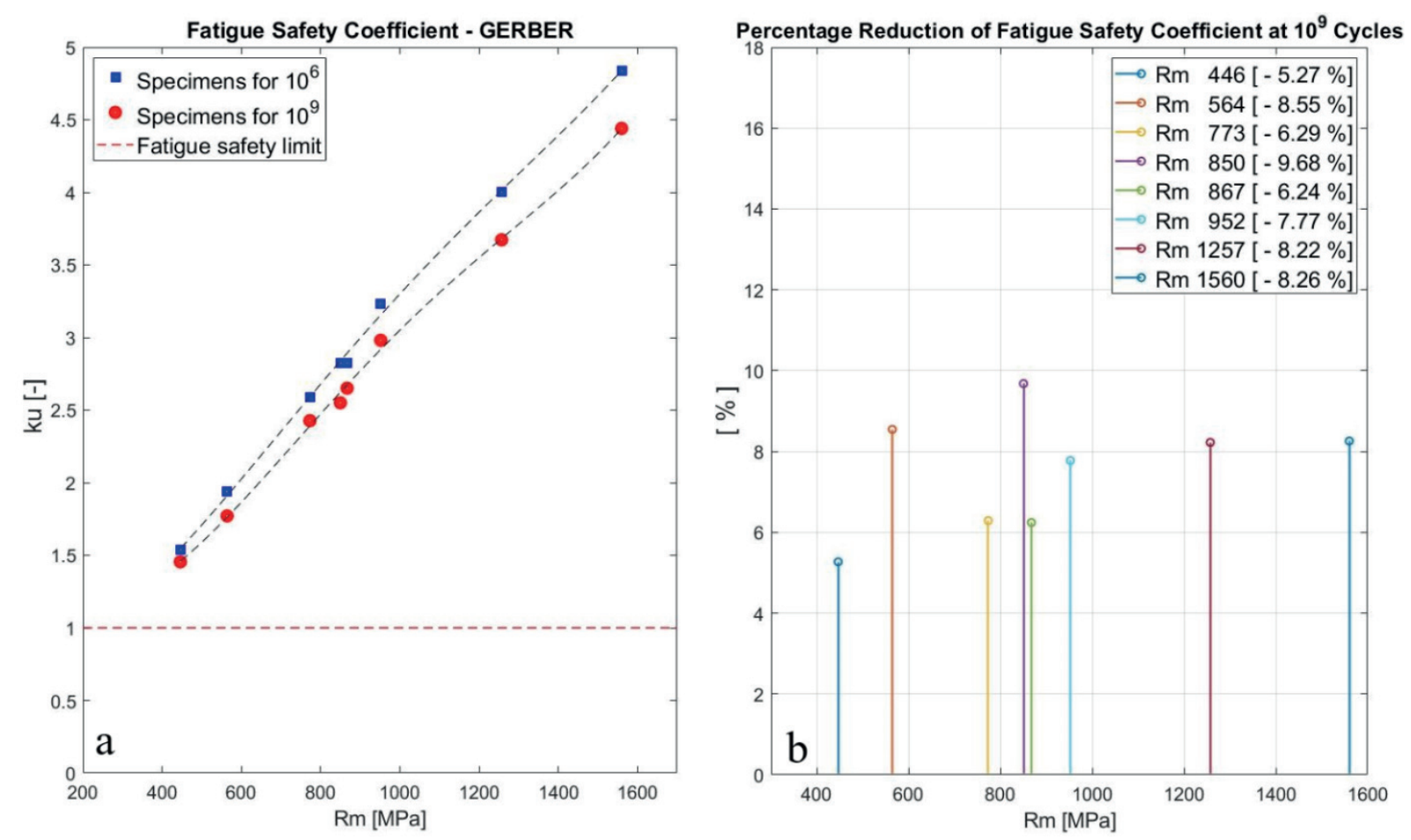

Figure 3 Fatigue safety coefficient $k_{u}(a)$ and percentage reduction of $k_{u}(b)$ - Gerber

Table 4 Specimens for the safety coefficient $k_{u}$ for Gerber

\begin{tabular}{ccccccccc}
\hline Specimens & 1 & 2 & 3 & 4 & 5 & 6 & 7 & 8 \\
\hline$k_{u}$ for $10^{6}$ & 1.54 & 1.94 & 2.59 & 2.82 & 2.82 & 3.23 & 4.0 & 4.84 \\
$k_{u}$ for $10^{9}$ & 1.45 & 1.77 & 2.43 & 2.55 & 2.65 & 2.98 & 3.67 & 4.44 \\
\hline$\%$ Reduction $k_{u}$ & -5.27 & -8.55 & -6.29 & -9.68 & -6.24 & -7.77 & -8.22 & -8.26 \\
\hline
\end{tabular}
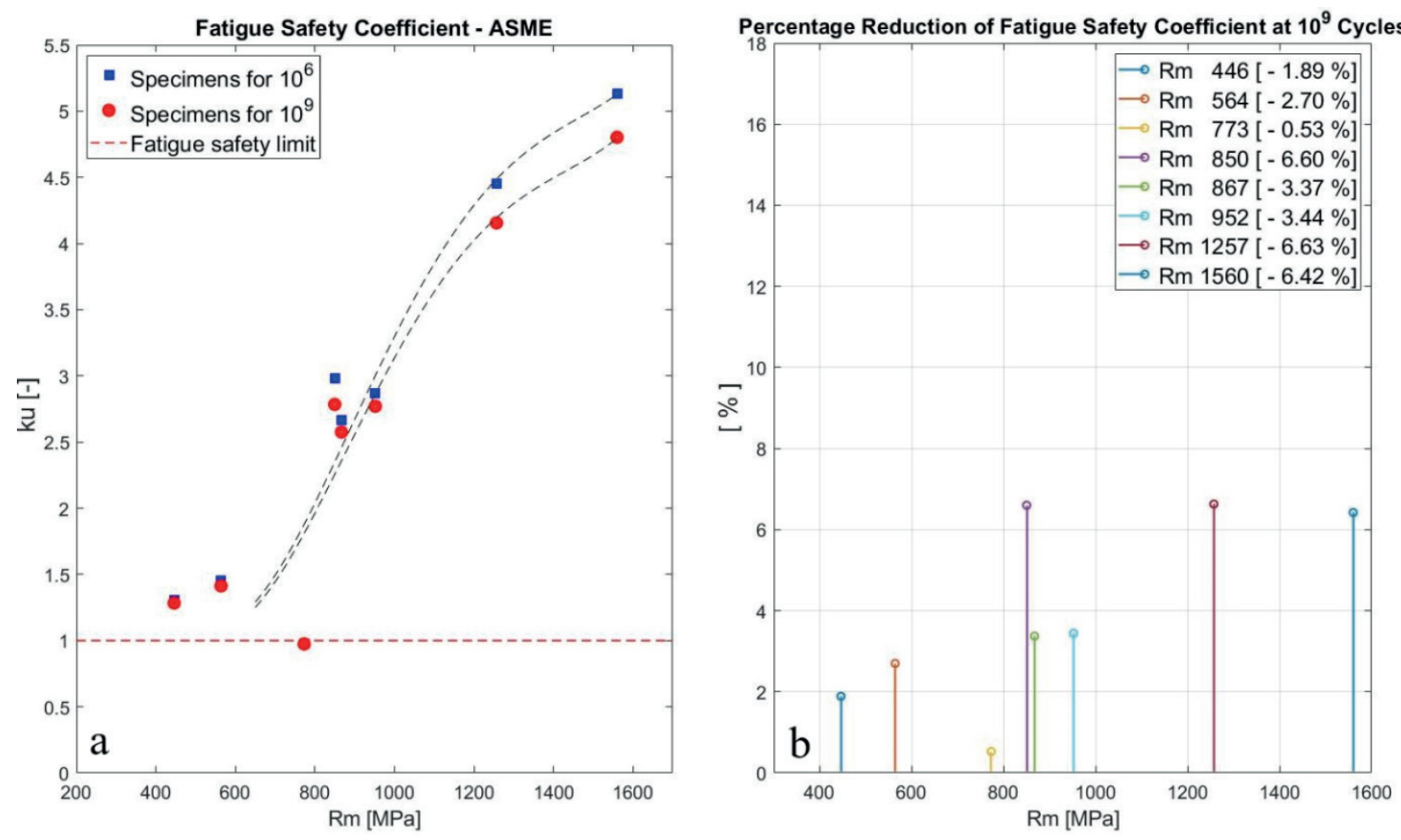

Figure 4 Fatigue safety coefficient $k_{u}(a)$ and percentage reduction of $k_{u}(b)$ - ASME 
Table 5 Specimens for the safety coefficient $k_{u}$ for ASME

\begin{tabular}{|c|c|c|c|c|c|c|c|c|}
\hline Specimens & 1 & 2 & 3 & 4 & 5 & 6 & 7 & 8 \\
\hline$k_{u}$ pre $10^{6}$ & 1.31 & 1.45 & 0.98 & 2.98 & 2.67 & 2.87 & 4.45 & 5.13 \\
\hline$k_{u}$ pre $10^{9}$ & 1.28 & 1.41 & 0.97 & 2.78 & 2.58 & 2.77 & 4.16 & 4.80 \\
\hline$\%$ Reduction $k_{u}$ & -1.89 & -2.7 & -0.53 & -6.60 & -3.37 & -3.44 & -6.63 & -6.42 \\
\hline
\end{tabular}
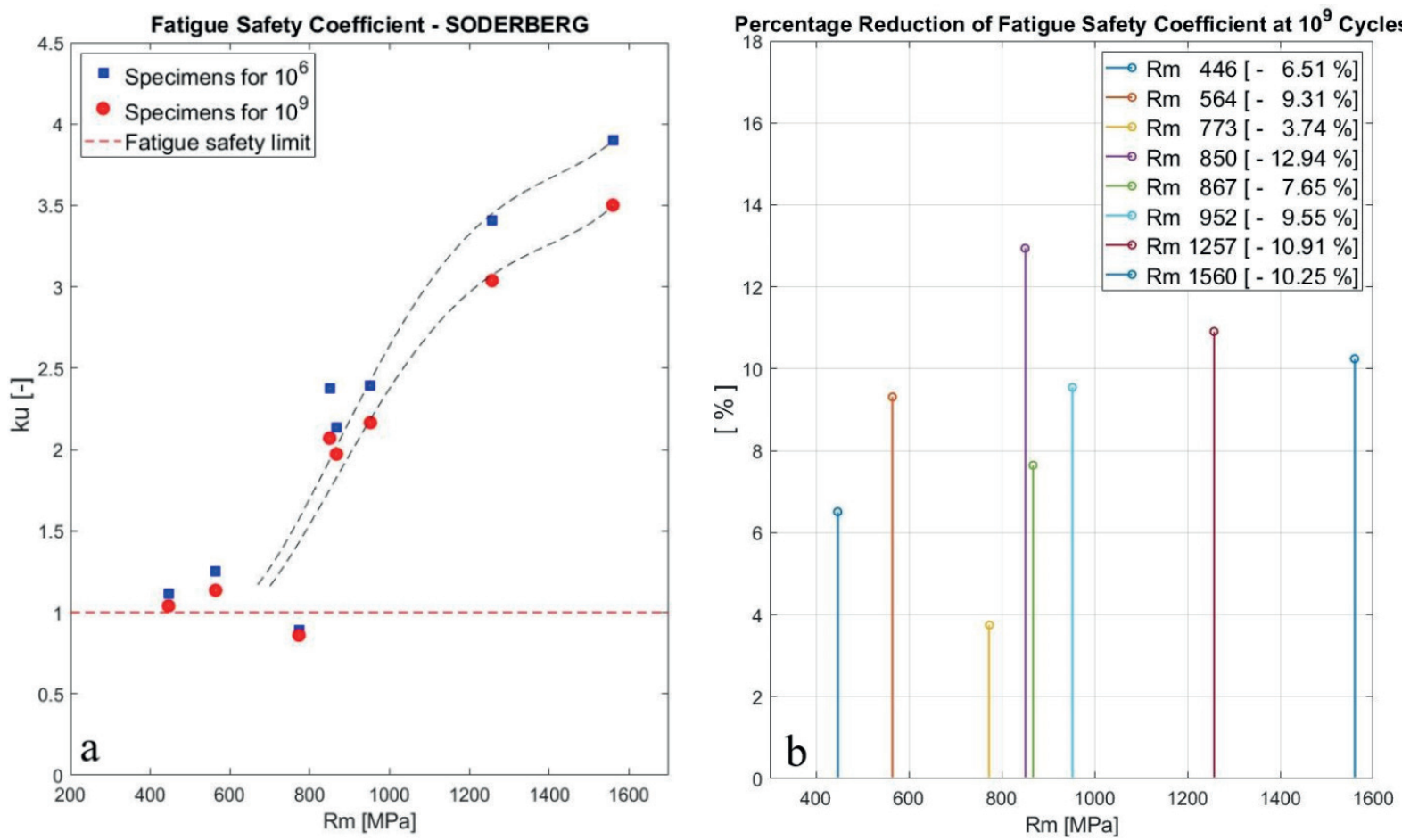

Figure 5 Fatigue safety coefficient $k_{u}(a)$ and percentage reduction of $k_{u}(b)$ - Soderberg

Table 6 Specimens for the safety coefficient $k_{u}$ for Soderberg

\begin{tabular}{cccccccccc}
\hline Specimens & 1 & 2 & 3 & 4 & 5 & 6 & 7 & 8 \\
\hline$k_{u}$ for $10^{6}$ & 1.11 & 1.25 & 0.89 & 2.38 & 2.14 & 2.39 & 3.41 & 3.90 \\
$k_{u}$ for $10^{9}$ & 1.04 & 1.14 & 0.86 & 2.07 & 1.97 & 2.17 & 3.04 & 3.5 \\
\hline \% Reduction $k_{u}$ & -6.51 & -9.31 & -3.74 & -12.94 & -7.65 & -9.55 & -10.91 & -10.25 \\
\hline
\end{tabular}

\section{Conclusions}

Taking into account the performed experimental work, the following can be stated:

- Dependence $\sigma_{a}=f(N)$ shows a decreasing character after the so - called basic number of cycles $N_{c}=10^{6}$ to $10^{7}$ cycles.

- The obtained values of the fatigue limit $\sigma_{c}$ at the so called basic number of cycles are overestimated.

- Determining the fatigue safety coefficient beyond the so - called basic number of cycles $\mathrm{N}_{\mathrm{c}}$ is therefore desirable.

- These facts must be respected in a qualified choice of structural steel if the component or equipment will work in real operation in the region of ultra - high numbers of load cycles.

\section{Acknowledgements}

The research was supported by the projects No. APVV - 16 - 0276, APVV - 18 - 0450, VEGA No. 1/0951/17 and project KEGA No. 012 ZU - 4/2019 and by the project of Operational Program Research and Innovation: "Research and development activities of the University of Zilina in the Industry of 21st century in the field of materials and nanotechnologies", No. 313011T426, co - funded by the European Regional Development Fund. 


\section{References}

[1] BATHIAS, C. There is no infinite fatigue life in metallic materials. Fatigue and Fracture of Engineering Materials and Structures [online]. 1999, 22(7), p. 559-565. ISSN 1460-2695. Available from: https://doi.org/10.1046/j.14602695.1999.00183.x

[2] BATHIAS, C., PARIS, P. C. Gigacycle fatigue in mechanical practice. New York, NY: Marcel Dekker, 1999. ISBN 0-8247-2313-9.

[3] BELAN, J., KUCHARIKOVA, L., TILlOVA, E., CHALUPOVA, M. Three-point bending fatigue test of TiAl6V4 titanium alloy at room temperature. Advances in Materials Science and Engineering [online]. 2019, 2842416. ISSN 1687-8434, eISSN 1687-8442. Available from: https://doi.org/10.1155/2019/2842416

[4] BOKUVKA, O., NICOLETTO, G., KUNZ, L., PALCEK, P., CHALUPOVA, M. Low and high frequency fatigue testing. Zilina, Slovakia: EDIS, University of Zilina, 2002. ISBN 80-8070-011-7.

[5] Bokuvka, O., NiCOletTo, G., GUAgliano, M., KUNZ, L., PALCEK, P., NOVY, F., CHALUPOVA, M. Fatigue of materials at low and high frequency loading. Zilina, Slovakia: EDIS, University of Zilina, 2014. ISBN 978-80-554-0857-6.

[6] KAZYMYROVICH, V. Very high cycle fatigue of engineering materials - a literature review. Karlstad: Karlstad University, 2009. ISSN 1403-8099, ISBN 978-91-7063-246-4.

[7] VASKO, A., BELAN, J., KUCHARIKOVA, L., TILLOVA, E. Low and high frequency fatigue tests of nodular cast irons. Metalurgija - Metallurgy. 2017, 56(1-2), p. 25-28. ISSN 0543-5846.

[8] SKOCOVSKY, P., PALCEK, P., KONECNA, R., VARKOLY, L. Structural materials (in Slovak). Zilina, Slovakia: EDIS, University of Zilina, 2000. ISBN: 80-7100-608-4.

[9] NOVY, F., ULEWICZ, R., BOKUVKA, O., TRSKO, L., LAGO, J. Reliability and safety of structural elements in the gigacycle region of loading. Communications - Scientific Letters of the University of Zilina [online]. 2016, 18(3), p. 83-87. ISSN 1335-4205, eISSN 2585-7878. Available from: http://komunikacie.uniza.sk/index.php/communications/ article/view/315

[10] BOKUVKA, O., JAMBOR, M., HRCEK, S., STEININGER, J., NOVY, F., TRSKO, L. Design of shaft respecting the fatigue limit for ultra-high number of cycles. Periodica Polytechnica Transportation Engineering. 2019, 47(1), p. 6 -12. ISSN 0303-7800, eISSN 1587-3811. Available from: https://doi.org/10.3311/PPtr.11562

[11] FATURIK, L., HRCEK, S., TRSKO, L., BOKUVKA, O. Comparison of structural design in high and ultra-high cycle fatigue region. Transactions of FAMENA. 2014, 38(4), p. 1-12. ISSN 1333-1124.

[12] BUDYNAS, R. G., NISBETT, J. K., SHIGLEY, J. E. Shigley's mechanical engineering design. New York: McGraw-Hill, 2011. ISBN 978-0-07-339820-4.

[13] GUJAR, R. A., BHASKAR, S. V. Shaft design under fatigue loading by using modified goodman method. International Journal of Engineering Research and Applications. 2013, 3(4), p. 1061-1066. ISSN 2248-9622.

[14] TRSKO, L., NOVY, F., BOKUVKA, O., JAMBOR, M. Ultrasonic fatigue testing in the tension-compression mode. Journal of Visualized Experiments [online]. 2018, 133, 57007. eISSN 1940-087X. Available from: https://doi.org/10.3791/57007

[15] BATHIAS, C. Piezoelectric fatigue testing machines and devices. International Journal of Fatigue [online]. 2006, 28, p. 1438-1445. ISSN 0142-1123. Available from: https://doi.org/10.1016/j.ijfatigue.2005.09.020 